\title{
The Costs and Labour of Whistleblowing: Bodily Vulnerability and Post-disclosure Survival
}

\author{
Kate Kenny ${ }^{1}$ (1) $\cdot$ Marianna Fotaki ${ }^{2}$
}

Received: 18 November 2020 / Accepted: 27 November 2021 / Published online: 27 December 2021

(c) The Author(s) 2021

\begin{abstract}
Whistleblowers are a vital means of protecting society because they provide information about serious wrongdoing. And yet, people who speak up can suffer. Even so, debates on whistleblowing focus on compelling employees to come forward, often overlooking the risk involved. Theoretical understanding of whistleblowers' post-disclosure experience is weak because tangible and material impacts are poorly understood due partly to a lack of empirical detail on the financial costs of speaking out. To address this, we present findings from a novel empirical study surveying whistleblowers. We demonstrate how whistleblowers who leave their role as a result of speaking out can lose both the financial and temporal resources necessary to redevelop their livelihoods post-disclosure. We also show how associated costs involving significant legal and health expenditure can rise. Based on these insights, our first contribution is to present a new conceptual framing of post-disclosure experiences, drawing on feminist theory, that emphasizes the bodily vulnerability of whistleblowers and their families. Our second contribution repositions whistleblowing as a form of labour defending against precarity, which involves new expenses, takes significant time, and often must be carried out with depleted income. Bringing forth the intersubjective aspect of the whistleblowing experience, our study shows how both the post-disclosure survival of whistleblowers, and their capacity to speak, depend on institutional supports or, in their absence, on personal networks. By reconceptualizing post-disclosure experiences in this way-as material, embodied and intersubjective-practical implications for whistleblower advocacy and policy emerge, alongside contributions to theoretical debates. Reversing typical formulations in business ethics, we turn extant debates on the ethical duty of employees to speak up against wrongdoing on their heads. We argue instead for a responsibility to protect whistleblowers exposed to vulnerability, a duty owed by those upon whose behalf they speak.
\end{abstract}

Keywords Whistleblower rewards $\cdot$ Feminist theory $\cdot$ Financial impact $\cdot$ Precarity $\cdot$ Retaliation $\cdot$ Cost of Whistleblowing

\section{Introduction}

Whistleblowing highlights wrongdoing in public, private and non-profit organizations, helping avoid disasters, ensuring accountability in organizations and upholding transparency in democratic institutions (Devine \& Maassarani, 2011; Heimstädt \& Dobusch, 2018; Su \& Xing, 2018). Whistleblowers serve organizations by detecting more fraud and

Kate Kenny

Kate.kenny@nuigalway.ie

Marianna Fotaki

Marianna.Fotaki@wbs.ac.uk

1 JE Cairnes School of Business and Whitaker Institute, NUI Galway, Galway, Ireland

2 Warwick Business School, University of Warwick, Coventry, UK other serious economic crimes than other internal policing and audit methods (ACFE, 2018). They help prevent reputational damage and costly legal battles (Stubben \& Welch, 2020; Vandekerckhove et al., 2013). For the rest of us, they make the world safer. Whistleblowers risk much when they speak out. Yet, there are few resources available to help them, and a poor understanding of the risk they incur.

Extant theory in business ethics tends to perceive the whistleblower as an abstract, disembodied figure. Key questions include whether or not whistleblowing should be considered a positive ethical duty, regardless of the risk to the individual involved (Ceva \& Bocchiola, 2019; Vandekerckhove \& Tsahuridu, 2010). Other studies focus on the whistleblower as a brave parrhesiast-a speaker of truth to power who risks all-without examining the specifics of these risks and what they mean for the individual and their family. To understand the risks for would-be whistleblowers, 
we must understand the impacts and costs for those who speak up, including the material consequences for whistleblowers and their dependents. Research that does explicate the costs of speaking out for the discloser tends to focus on impacts on career, family, mental and physical health (Bjørkelo, 2013; Fotaki et al., 2015; Glazer \& Glazer, 1989; Kenny, 2019; Lennane, 2012; Wilkies et al., 2011), while the more tangible costs remain vague. Studies that focus on laws compensating people for retaliatory actions on the part of organizations that result in depleted income-for example, dismissal or demotion —overlook whistleblowers' own experiences of financial detriment (Butler et al., 2020; Nyreröd \& Spagnolo, 2019). Detailed research on the actual impact of speaking out, for example, on one's income, and the financial costs of disclosing, remains rare. This gives rise to the following questions: if whistleblowing about wrongdoing is seen as an employee's duty, and yet the employee is asked to risk so much to speak out, is this just? Should there be a reciprocal duty on society to help alleviate this risk? To assess this, can and should we learn more about the specific vulnerabilities to which whistleblowers can be exposed?

Our current lack of understanding of these aspects leads to a persistent, stereotypical view of whistleblowers that posits them as heroes or traitors but rarely as real human beings struggling with the same financial burdens as everyone else (Grant, 2002; Hersch, 2002). Yet, the costs of whistleblowing can be high. Approximately one in every five employees disclosing wrongdoing suffers some form of reprisal, which can involve leaving one's role as a result of the disclosure. Without a clearer understanding of the tangible impacts, conceptual understandings of post-disclosure experiences remain anaemic, while policy responses meant to protect whistleblowers remain inadequate. So long as the financial impact of whistleblowing is poorly understood and under-specified, whistleblowers who leave their role will continue to struggle to plan for life post-disclosure. This exacerbates the generalized sense that whistleblowing can have negative impacts on people's well-being and thus should be avoided (Alford, 2001; Smith, 2014). The result is a "chill effect" on would-be whistleblowers; fewer come forward for fear of financial repercussions post-disclosure, (Cho \& Song, 2015; De Graaf, 2010). A further practical difficulty emerging from the status quo relates to providing effective assistance and advice for those who experience financial detriment after speaking out (Qusqas \& Kleiner, 2001). Lack of research means an absence of meaningful and robust supports. Where whistleblowing legislation exists and has a remedy for detriment built in, as in some countries, it is typically found to benefit relatively few people (European Commission, 2018). The same is true for financial rewards systems for whistleblowers (Butler et al., 2020). Meanwhile, advocacy and support groups struggle to provide advice on financial recovery post-disclosure; scarcity of funding typically means they are limited to providing essential legal advice (Eisenstadt \& Pacella, 2018; Nyreröd \& Spagnolo, 2019). Even where funding permits, groups lack empirical information about the financial impacts of disclosure upon which to base advice. Therefore, the persistent conceptual lacuna in how we currently understand whistleblowing and its impacts, restricts our ability to meaningfully support whistleblowers. Meanwhile, somewhat incongruently, theoretical conceptualizations of whistleblowing downplay risk, while compelling employees to come forward and fulfil their ethical duty. Our study aims to address this problem. We argue that overlooking the material and relatedly embodied aspects of whistleblower survival is problematic both for themselves and for those who help them. Ignoring these aspects, we underestimate the profound and multiple risks whistleblowers face for speaking out.

This article builds upon existing approaches by delving deeper into the impacts of disclosing wrongdoing, to better understand these risks for would-be whistleblowers. Specifically, we address a persistent lack of empirically driven theorization of the tangible, material impacts on whistleblowers including financial struggles. We draw on unique empirical data on the financial and time-related costs of whistleblowing from the perspective of those who leave their former role due to their disclosure. An eighteen-month study carried out in 2017 and 2018 examined both the tangible and intangible impacts of whistleblowing via a survey of 92 individuals. We aimed to document the extent and types of impact and costs people incurred as a result of speaking out. Participants were drawn from various sectors that included public, private and non-profit, and had spoken up about many types of wrongdoing. Our results provide detail on the significant reduction in financial and temporal resources necessary to redevelop one's livelihood post-disclosure, incurred by whistleblowers who leave their role as a result of speaking out. We also demonstrate how concurrent costs can rise alongside a time burden. We analyse the data through a feminist theory lens that emphasizes bodily vulnerability and exposure to dispossession and privation (Butler, 2016; Butler \& Athanasiou, 2013). This analysis allows us to theorize the impact of whistleblowing on individuals' livelihood and their families' well-being. It also helps us to conceptualize post-disclosure survival in more depth. We show how, to date, theoretical lacunae persist in the extant whistleblowing literature (Kenny, 2019; Olesen, 2018). These lacunae, we suggest, echo a dominant view in social science reflecting the masculinist ideal of an autonomous, abstract figure in which relationality with others, and the primary vulnerability of the body, are ignored. Indeed, much of the literature on whistleblowers focuses on their individual motives (Taylor \& Curtis, 2010) or identity (Vadera et al., 2009). In contrast, theorizing whistleblower experiences through a feminist lens of embodied relationality (Kenny \& Fotaki, 
2015) enables a fuller comprehension of hitherto-neglected material impacts. It also prompts our recommendations for policy interventions centred on developing an ethics of care towards whistleblowers as caring subjects protecting society. Feminists of various persuasions have recognized that such "care work" which is not merely about moral sentiments but involves embodied work (Antoni et al., 2020; Fotaki et al., 2020) is often precisely the type of work that the market does not value (Ferguson et al., 2018). Furthermore, we stress whistleblowers' dependence on institutions, infrastructures and their relational interdependence vis-à-vis other subjects for their material survival after speaking up against wrongdoing. Our work thus contributes to a growing movement engaging feminist ethics to valuably reframe critical issues in organizations (Vacchani \& Pullen, 2019; Pullen \& Rhodes, 2014; Vacchani, 2012) and to debates on relationality in management and business studies (see De Vaujany et al., 2018; Fotaki, 2017; Küpers, 2016; Mandalaki \& Fotaki, 2020; Tyler, 2019).

Our specific contributions are: first, we reframe postdisclosure experiences as involving the bodily vulnerability of whistleblowers and their families, and we detail the constituent aspects of this, thus adding to debates on the costs of disclosure, its risks and the ethics of compelling whistleblowing as a duty. Rather than abstract figures, whistleblowers are embodied, relational beings, and like us all, their bodies are vulnerable to demise. To date, the specific vulnerabilities of post-disclosure experiences, including income depletion, related costs of whistleblowing and time burdens, are overlooked, alongside other attributes that contribute to the availability of money and time (e.g. career prospects and supportive infrastructures for speaking out). Instead, the implied focus is on compelling whistleblowers to come forward as a duty to society, regardless of the potential impact on their capacity to survive. In contrast, inspired by a feminist approach drawing attention to the infrastructural and material supports that enable survivability and liveability (Butler, 2016), our study provides rich detail, enabling a reconsideration of current approaches.

This gives rise to our second contribution; we show how the post-disclosure experience can be a visceral project of defending against exposure to the consequences of speaking out and putting oneself outside the dominant organizational norms, requiring a new kind of affective and embodied labour. To date, critical material aspects-the body and intersubjective relations-have been downplayed in academic studies of whistleblowing. Feminist approaches to power and resistance emphasize a relational view of subjectivity (Butler \& Athanasiou, 2013, p. 3), helping us to see that embodiment and relationality form key aspects. The post-disclosure survival of whistleblowers appears to depend upon the institutional supports available or, in their absence, upon personal networks that must be mobilized. Drawing on the empirical findings from our study and feminist theorizing on embodied vulnerability, we provide a reframing of this phase of disclosure. We thus argue that whistleblowing in cases of job loss must be reframed as a form of labour that incurs new expenses, takes significant time and often must be carried out with depleted income.

Overall, this study gives rise to a new theory of whistleblowing as defence against precarious living which emerges from the extensive empirical study and privileges relational interdependence on institutions, infrastructure and other subjects. We build on extant theory to show how the radical and bodily vulnerability of the whistleblower, and that of their families and dependents, should be centre-stage in debates on whether and how they have a duty to disclose. Related to this, support for whistleblowers must be reframed as enhancing their capacity to defend against harmful impacts, through the labour involved in post-disclosure survival. This has important policy implications for helping to avert the undesirable consequences of retaliation that many whistleblowers experience, particularly in light of the complexity and cumulative nature of negative impacts. Our findings compel a rethinking of how whistleblower support ought to be delivered, with a specific focus on infrastructural supports enabling them to survive.

The article proceeds as follows. We begin with an outline of research on the impacts of whistleblowing; we show that while extensive and shedding valuable light on critical aspects of this phenomenon, current understandings of one important aspect - the tangible impact of whistleblowers' post-disclosure experiences-remain lacking. We then present the feminist theoretical lens that provides inspiration for our analysis. After detailing our method, our findings demonstrate how whistleblowers who leave their current role as a result of speaking out can see incomes deplete, costs go up, and a resulting diminishment of quality of life for them and their families. Next, we analyse our data and describe emerging contributions for theory and practice.

\section{Whistleblowing Risk: Exposures and Vulnerabilities}

Whistleblowing can involve risk, but a detailed understanding of the nature of this risk is lacking. In business ethics, the question of whether or not whistleblowing should be seen as a duty is an ongoing debate. The idea is that employees are morally obliged to blow the whistle if they witness wrongdoing (Ceva \& Bocchiola, 2019). This is because, as an organizational member, an employee has an obligation to help uphold the mandate given to the organization by society - they possess a 'positive duty', that is, a duty whose neglect warrants moral blame. Making employees responsible for whistleblowing is a significant aspect of whistleblowing discourse and debate for many years (Tsahuridu \& Vandekerckhove, 2008; Vandekerckhove \& Tsahuridu, 
2010). However, for Vandekerckhove and Tsahuridu (2010), this trend is problematic. Whistleblowing (understood as an act of reporting wrongdoing) is more complex in many settings in which such dilemmas play out, not least because the risk to the individual whistleblower is poorly understood. "we can reasonably legislate whistleblowing as a positive duty only if we can also minimize the risk of retaliation to the whistleblower" (ibid, p. 376). In other words, where we cannot safely minimize this risk, it is not reasonable to compel them to come forward. The authors call for caution when arguing the case for whistleblowing as a positive duty. Whistleblowing must be seen as a "highly critical, risky and unpredictable process, both for those who speak up on the work floor as well as for those taking it further up the ladder" (Vandekerckhove \& Langenberg, 2012, p. 40).

A recent trend within business ethics and organization studies has been to conceptualize whistleblowing as parrhesia-speaking truth to power and incurring risk to the self in the process. This approach examines what it is to live as an ethical truth-teller and be the subject breaking free from powerful norms of complicity and silence to speak out (Kenny et al., 2020; Mansbach, 2009; Munro, 2017; Weiskopf \& Willmott, 2013). Such studies show how one's sense of self as parrhesiast comes into being from enacting the position of whistleblower itself. While becoming a whistleblower carries substantial and multiple risks to the truth-tellers' survival and well-being, many studies appear to assume the risk is embraced-or at least known beforehand-by the whistleblower, who speaks out regardless. As with debates on the positive duty of whistleblowing, the risks of speaking out for one's professional standing, health and well-being or survival, tend not to be dwelt on by scholars but are mentioned in passing as an unfortunate side-effect. This lack of attention may relate to the fact that whistleblowing experiences are often theorized in the abstract, without attention to the real-life stories of those who speak up and the risks they incur along with their families (see Kenny, 2019 for discussion). And yet, current trends in both policy and academic discourse alike increasingly focus on compelling employees to come forward if they witness wrongdoing.

Given this focus, the question we ask is: what do we know about the risks involved for whistleblowers? To understand the risks, we must understand the costs. Valuable and wellestablished literature exists detailing the nature and extent of whistleblower reprisals, ranging from isolation, demotion, career stagnation, detriments to health, mental health, well-being, relationships and career prospects (Kenny et al., 2019; Lennane, 2012; Cortina \& Magley, 2003; Alford, 2001; Fotaki \& Kenny, 2019; Glazer \& Glazer, 1989). Such research has yielded in-depth insight into the potential dangers of speaking out. One aspect, however, remains underresearched. Financial impacts are frequently mentioned anecdotally but rarely specified (Devine, 2015; Qusqas \& Kleiner, 2001; Vandekerckhove, 2006). Some studies explore tangible post-disclosure experiences, including financial aspects such as income and cost impact, albeit research is limited as detailed next.

\section{Understanding Income Impact}

Speaking out can attract retaliation from within the organization (Kenny et al., 2019; Verschoor, 2012; Rehg et al., 2008, p. 222), with studies suggesting this occurs in approximately $20 \%$ of cases (TI Ireland, 2017). Whistleblower retaliation can lead to people leaving their current role (Alford, 2001; Dworkin \& Baucus, 1998; Glazer \& Glazer, 1989; Lennane, 2012; Miethe, 1999; Parmerlee et al., 1982; Rothschild \& Miethe, 1999;). Isolation by colleagues, restricted access to organizational systems and oppressive working conditions including micro-management can engender a desire to resign (Alford, 2001; Devine \& Maassarani, 2011; Kenny, 2019). Other whistleblowers find themselves the target of more direct retaliatory tactics, including demotion, dismissal or both (Qusqas \& Kleiner, 2001). This can cost the whistleblower in a number of ways. First, there is the obvious reduction in income resulting from demotion, dismissal and the period of unemployment after leaving one's role. One's opportunity to find work again can be further hampered by being blacklisted either formally or informally in their industry (Eisenstadt \& Pacella, 2018; Mesmer-Magnus \& Viswesvaran, 2005). Blacklisting is prevalent even though many whistleblowers had been, prior to their disclosures, "high-achieving, respected, exceptionally committed members of their employing organization" (Rothschild, 2013, p. 653). While income depletion can thus be a feature of whistleblowing cases, at present little empirical information exists on its extent or specific nature.

\section{Understanding Cost Impact}

Just as income goes down, expenses go up (Lennane, 2012). People can find themselves involved in lengthy court cases or tribunal proceedings, incurring legal costs with a severely reduced income or none at all (Devine \& Maassarani, 2011; Glazer \& Glazer, 1989). In many countries, whistleblowing claims are dealt with under an employment rights framework meaning the whistleblower is liable for legal costs, even when their case succeeds (APPG, 2020; IBA, 2021). Health costs can also increase: retaliation from co-workers and managers, social isolation, career and financial pressures can cause stress. Whistleblowers can be legally restricted in what they can disclose to others, which exacerbates anxiety and isolation (Alford, 2007; Gunsalus, 1998; Kenny et al., 2019; Oliver, 2003). During the crucial post-disclosure phase, whistleblowers can find it difficult to relate to loved 
ones who do not understand the details of a complex case. Related problems of post-traumatic stress disorder (PTSD) and moral injury can lead to severe mental health impacts for those who speak out (Kenny et al., 2019; Fotaki et al., 2015); including clinical depression, anxiety, heart problems, hypertension and related health concerns (Lennane, 2012; Rothschild, 2013). Dealing with these mental and physical impacts costs money (Jackson et al., 2010; Peters et al., 2011). Thus far, however, there has been little systematic evidence of these costs, particularly concerning the impact upon a whistleblower's finances.

\section{Provision of Appropriate Financial Supports}

While the impacts of speaking out can be extreme, meaningful financial supports for whistleblowers who suffer material detriments post-disclosure are typically scarce (Alford, 2001; Devine \& Maassarani, 2011). Studies in this area tend to fall into two camps. First is a focus on reforming legislation so that if whistleblowers do experience demotion or dismissal, they can seek a financial remedy through the courts (Devine, 2013; Government Accountability Project, 2018; Martin, 2013). Research suggests that few people benefit from such schemes, with for example, the UK PIDA law yielding a 12\% success rate (APPG, 2020; IBA, 2021). While valuable, an exclusively legal focus limits our understanding of post-disclosure experiences of individuals and how laws impact these, including their well-being. The second strand of research into post-disclosure financial support examines the payments of rewards to encourage whistleblowers to come forward. They originate in the idea that financial 'bounties' will compensate whistleblowers for income depletion and cost escalation (see for example, the US Dodd-Frank/SEC whistleblower program for financial services, Government Accountability Project, 2018). Studies indicate the likelihood of a whistleblowing bounty claim in the US SEC being successful for the whistleblower is minuscule, with less than $1 \%$ of applications accepted (Government Accountability Project, 2016). Meanwhile, research into the efficacy of financial incentives tends to focus on whether bounties motivate disclosures, and studies are carried out in experimental settings in which volunteers assess hypothetical scenarios (e.g. Feldman \& Lobel, 2010). Having reviewed the evidence on the impact speaking out has on whistleblowers and their families, we conclude that the existing research suggests two things. First is that existing schemes are not working for the majority of those they intend to serve, and second that they are based on flawed assumptions about the tangible and material experiences of speaking out on whistleblowers' lives and those of their families.

To understand the risks of whistleblowing disclosures, we must examine more closely the negative impacts that can result. On this point, one important aspect of whistleblower experiences post-disclosure-tangible, financial aspectsrequires further attention. Given the evident importance of financial stability for the well-being of a whistleblower and their family, we cannot reasonably assess the risks of this activity without paying attention to this. Rather than downplay risk, in this article, we foreground it. Specifically, we examine the material, embodied and relational aspects of disclosures, alongside the implications for the supports needed. Examining these aspects is critical if we are to support this group to have viable lives after speaking out, and provide the would-be whistleblowers with facts to make an informed decision on whether and how to speak out. We must fully understand what we are asking people to do when our policies and theories compel employees to put themselves at risk and fulfil their presumed ethical obligations to come forward and disclose wrongdoing. A feminist lens on embodied vulnerability and dispossession is useful for such an examination, because it focuses on bodily precarity as a means of resisting power and domination. Judith Butler's theorizing of the shared vulnerability of the human body (Butler, 2004a, 2004b, 2009, 2016) is particularly useful for highlighting the material impacts of speaking out for many whistleblowers as well as for identifying the support infrastructures society must ensure before encouraging them to report wrongdoing.

\section{Feminist Ethics: From Abstract Figures to Embodied Subjects}

To enhance extant understandings and build upon dominant approaches, we draw on the feminist critique of business ethics (Fotaki, 2019; Vacchani \& Pullen, 2019; Pullen \& Rhodes, 2014). On this view, to ignore the bodies of those who are subject to the power of organizations, both by working in them and being affected by them, effectively upholds the "reproduction of inequality and injustice" that organizations can exacerbate (Butler, 2016, p. 20). Thus, the authors argue for "corporeal ethics", a concept that foregrounds the body and its materiality in business ethics theorizing, recognizing that the body has been overlooked to date. In rare instances where it is included, it is treated only in discursive and abstract terms (Fotaki et al., 2014; Kenny \& Fotaki, 2015; Pullen and Rhodes, 2015).

A recent approach has been to draw on Butler's notion of precarity, which centres on the fact that we are beings with bodies. Our bodies are vulnerable from birth to exposure and destruction of various kinds whether war, famine or poverty. The radical precarity and vulnerability of the body is the shared human experience, regardless of wealth or circumstance, "To live is always to live a life that is at risk from the outset", and which can be "expunged quite suddenly from the outside and for reasons that are not always under one's 
control" (Butler, 2009: 30). Of course, while precarity is a "generalizable condition" (2009: 23), the risk of destruction is not equally distributed. Certain categories of persons can be made distinctly vulnerable, particularly those rendered less than human by the framings generated by powerful entities. As scholars have demonstrated, organizations can contribute to and exacerbate the exposure of certain subjects to risk through, for example, categorizing and framing groups in ways that deny their status as 'valid' human subjects and thus foreclose recognition of their vulnerability (Fotaki, 2017; Kenny, 2018; Tyler, 2019). As the drive for profit intensifies under neoliberal capitalism, certain bodies including migrant labourers are increasingly disposable (Fotaki, 2021).

The law, and public and academic discourse, can all contribute to this framing, as Butler (2009) describes in a discussion of the exclusions pertaining to the human rights discourse, its categories and its application in legislation and policy. For some critics, Butler does not go far enough in engaging with the material 'reality' of bodily experience (Lloyd, 2008). Instead, she tends to emphasize how our apprehension of the body is always mediated by discourse, and the relationality existing between bodies, arguing that these are very "real" to subjects and thus "matter" (Butler, 1993). In addition, while Butler's earlier work focussed mainly on the discursive aspects of bodily experience (e.g. Butler 1990), we note a renewed focus on material and infrastructural concerns in later work. Such a critical inflection inspires a deeper understanding of precarity and resistance (e.g. Butler, 2016; Butler \& Athanasiou, 2013).

These points notwithstanding, beginning with the concept of bodily vulnerability can help us to understand how conditions can emerge that enable or deny, a liveable life for the subject (Butler, 2004a, 2004b, 2005, 2009, 2015). A feminist position holds that any consideration of ethics must, therefore, encompass how "every single body has a certain right to food and shelter, freedom to move and breathe protected from violence" and must protect the conditions by which these can be attained (Butler, 2016, p. 15). The interdependency of bodies in how these conditions come about is critical to understand; "...Part of what a body is... is its dependency on other bodies and networks of support...[and thus] it is not altogether right to conceive of individual bodies as completely distinct from one another". The point is not that distinctions between bodies should be seen as irrelevant. It is rather to emphasize that "if we conceptualize the political meaning of the human body without understanding those relations in which it lives and thrives, we fail to make the best possible case for the various political ends we seek to achieve" (Butler, 2016, p. 16). This suggests not just that a body is dependent on the network of others to which it belongs but that, despite its apparent boundaries, the body is "defined by the relations that make its own life and action possible" (Butler, 2016, p. 16).

In all cases, it is our social embeddedness that stands between ourselves and annihilation. Bodies affect each other in that they offer the capability for survival. The mutual interdependence of bodies means that "they can persist and act only when they are supported, by environments, by nutrition, by work, by modes of sociality and belonging" (Butler, 2015 , p. 84). Organizations and institutions play a key role in enabling this persistence, "there can be no embodied life without social and institutional support" (Butler, 2015, p. 84). This implies "a certain kind of dependency on infrastructure, understood complexly as environment, social relations, and networks of support and sustenance that cross the human, animal and technical divides" (Butler, 2015, p. 133). The denial of this infrastructure can lead to risk and exposure to precarious living. It can undoubtedly stymie any attempts at resistance or even the exercise of basic rights: "No-one moves without a supportive environment and set of technologies" (Butler, 2016, p. 15). When these fail, "our very capacity to exercise most basic rights is imperilled" (ibid).

In its focus on the relational and the body, a feminist approach runs counter to mainstream assumptions around the self as a "self-contained, proper(tied) liberal subject... "- a problematic concept that persists in Western thinking and dominates organizational studies and business ethics. Having its origins in economics and neoliberal ideology, on this view subjects are conceived as disembodied beings seeking to maximize their utility through acts of consumption ad infinitum (Fotaki, 2006). At worst, this liberal individualistic subject is "constituted through, and inhabited by, processes of de-subjectifying others, rendering them usable, employable, but then eventually into waste matter, or of no use: always available, always expendable" (Butler \& Athanasiou, 2013, p. 27).

Bringing these ideas together, central to any understanding of resistance to oppressive structures is an understanding of the body, its vulnerability to demise and its intrinsic dependence upon the "relations in which it lives and thrives". Institutions and infrastructures play a vital role in this dependence because they can enable or prevent the relationality needed for survival and struggle. More broadly, the "porosity of the bodily boundary" has distinct implications for ethics. Embodiment holds the promise of ethical engagement: the body is the "field of ethical enmeshment with others" (Butler, 2004b, p. 25, see also Tyler, 2019 for discussion). Echoing Levinas and Hegel, Butler argues that distinct ethical and political promise inherent to the "mutual vulnerability of embodied subjects" (see Tyler, 2019, drawing on Butler \& Athanasiou, 2013, Butler et al. 2016, see also Cavarero, 2000, 2007; Murphy, 2011). But recognizing this interdependence and mutual vulnerability obliges 
us to engage with the moral and political consequences by advocating necessary change in the policy arena (Antoni et al., 2020; Fotaki, 2017). As feminist organizational theorist Melissa Tyler (2019) argues, such aspects have important implications for how we think about organizations, their role in denying recognition and in their provision-or otherwise - of infrastructural support for particular groups including marginalized ones. In this article, they help us understand the experiences of whistleblowers who have left their roles due to speaking out. Drawing on these critical notions of the subject as vulnerable to injury and dispossession, and as inter-dependently co-constituted in and through relations to others, we interpret the findings from our empirical study to both, explain the neglect of embodiment and relationality in whistleblowing research, and argue for specific policies and interventions needed to address this.

\section{Research design and project planning}

The inspiration for this study came partially from our own experiences as researchers. We found in prior interviewbased research that whistleblowers often deny the vulnerability-including the material aspects—-that they experience (Kenny et al., 2019). This occurs when they speak to us as academics, and also, we observe, when speaking to journalists. We were aware that many had experienced financial loss but preferred to hide this. One man told us he borrowed smart suit jackets for interviews. Two participants asked us to interview them close to home because they could not even afford the cost of travel on train and/or bus. Others hid the fact that they must travel to meetings on the bus and reported feeling shame about their material circumstances having been depleted. The social stigma around wealth and status is internalized. Aware that whistleblowers in practice often downplay their material vulnerability, we became aware that a deeper understanding of these issues was essential. We thus aimed to examine the bodily vulnerabilities and exposures to risk experienced by whistleblowers.

Inspired by the alternative perspectives on ethical relations offered by feminist theory, we wished to focus on aspects of whistleblowing disclosures that are typically overlooked in extant research - and discussions of business ethics more broadly. These include tangible impacts that affect the bodily capacity for survival: financial resources including changes to income and expenditure as a result of speaking out, costs of attaining necessary care for mental health and physical impacts, the time costs of speaking out, the capacity to earn a living, attaining support through modes of belonging and access to the infrastructures that can help cope with these experiences to better enable survival for self and loved ones. We collected quantitative evidence on these aspects. Our study is among the first attempts to measure and quantify the tangible costs of disclosure for people who find themselves having to leave their current role as a result of speaking out. Our findings are supplemented by qualitative survey responses from whistleblowers, which provide useful background detail while not forming a substantive part of our data.

\section{Data collection and analysis}

\section{Survey Design}

Data collection proceeded in three phases: first, we reviewed relevant literature on whistleblowing and analysed pilot study interviews $(n=24)$ with whistleblowers in banking, health, social care, insurance and IT, collected as part of another project with similar aims (Kenny \& Fotaki, 2019). We elicited dominant themes and topics relating to the costs of disclosure and presented these for discussion with practitioners in human resources and compliance, and whistleblowers, at an event hosted in London in June $2017(\mathrm{n}=28)$ and Cambridge in September 2017 $(n=40)$. We sought advice from an international advisory team of expert academics, advocates and whistleblowers appointed to the project $(n=7)$. We developed and refined our survey instrument based on their feedback, practitioner input and our analysis. Our aim in these efforts was to understand how best to study the tangible impacts of disclosure (financial and otherwise), and capacity for survival post-disclosure. The complete survey is available in Appendix 1.

In designing the survey, categories specifying the type of wrongdoing disclosed [Q10], respondents' sectors [Q2], their ethical distance to the wrongdoing [Q12], and how and with whom the concern was raised [Q17-19] were adapted primarily from a large-scale NGO survey of over 1000 whistleblowers (Vandekerckhove et al., 2013). Further details in these areas and relevant personal and situational characteristics were drawn from the previous studies (Cassematis \& Wortley, 2013; Near et al., 2004). This allowed for comparison of the preliminary results to the previous surveys for the purpose of instrument validation and provided potential covariates for analysis. Questions regarding loss of income, expenditure on health, response to changes in income and other continuous variables followed from studies in which income is itemized into specific areas then summed to obtain an aggregate (Davern et al., 2005; Foster \& Lound, 1993). This method reduces variance in income estimates, while itemization provides granularity for modelling purposes. Scholars have suggested that providing income bands to respondents may result in improved accuracy of responses as compared to continuous responses (ibid.). However, the variety 
of currencies and potential for very large ranges of values limit the applicability of income bands in our study, and, therefore, we used continuous responses. To assess income differential pre- and post-disclosure, we repeated this question to obtain the difference for each respondent.

\section{Survey Respondents}

The survey was part of a larger project which encompasses interviews with 58 whistleblowers and 17 experts, details of which are published elsewhere. We administered the survey to 92 whistleblowers (March-June 2018). Adapting a wellknown definition, we focussed on whistleblowers who had disclosed "illegal, immoral, or illegitimate practices under the control of their employers" to a party that was expected to act on it (Near \& Miceli, 1985). The majority of our participants (97\%) had left their role due to speaking out. Our advisory team members assisted in sharing the survey with relevant participants. We thus gathered respondents via snowball sampling. The majority $(70 \%)$ of study participants were based in the US, with the next largest group from the UK (16\%). The remaining 14\% were divided among Ireland (3), Switzerland (2), and Belgium, Australia, Sweden, South Africa, Romania and India (1 each). We included a range of sectors: federal and central government employees represented $32 \%$, followed by health (20\%) and education (10\%). Military and armed services, manufacturing, housing, leisure and local/state government workers were also represented. The geographical and sectoral makeup of our cohort is a result of convenience sampling. We acknowledge this is not an ideal sample strategy. It is, however, often necessary in cases where a target group is difficult to access, particularly in studies of whistleblowing (see also MesmerMagnus \& Viswesvaran, 2005). Country and culture characteristics can influence aspects of the whistleblowing process, including employees' perspectives on what constitutes wrongdoing and their likelihood to disclose (see Culiberg $\&$ Mihelič, 2016 for an overview). For this reason, scholars have called for a widening of research focus to countries beyond the US (Miceli et al., 2009). A broader spread of contexts from Norway to India, Croatia, South Korea and Malaysia has formed a welcome addition (Keenan, 2002; Miceli \& Near, 2013; Park et al., 2008; Sims \& Keenan, 1999; Tavakoli et al., 2003). In the context of our research, we note these studies focus on culture and context impacts on pre-disclosure behaviour, thus differing from our focus on the post-disclosure impacts of speaking up for the whistleblower. On this point, the existence of whistleblower protection legislation is perceived as a more influential factor in people's experiences, including retaliation impacts (Culiberg \& Mihelič, 2016). While there are varieties in legislation, in the majority of countries we surveyed, such legislation is in place except for Switzerland and India. Moreover, the different legal frameworks across jurisdictions and sectors tend to share a general absence of consideration for robust financial supports for whistleblowers (IBA, 2021), which forms our study's focus. While our design is appropriate to answer our research questions given the constraints, we do note the cultural specificity of our study with its focus on US and UK disclosers, an outcome of the difficulty in gaining access to the population we sought to study and the necessity to work with established whistleblower support and advocacy groups. Future studies will usefully examine finer-grained impacts of country context, culture and sector (Culiberg \& Mihelič, 2016; Park et al., 2008).

\section{Data Collection}

We used an anonymous survey technique found by previous studies to help examine the experiences of whistleblowers (Rothschild \& Miethe, 1999). We tested our survey instrument via a pilot survey of 12 people, which helped us refine our questions, and used software to disseminate the survey and aggregate results. Our study used appropriate ethical protocols given that we engaged with people who may be in a vulnerable position; we drew on guidelines set out by our funder and our institutions and experience in previous projects (Kenny et al., 2019, 2020). We gathered only IP addresses that were stored securely and enabled anonymous responses.

\section{Data Analysis}

Approximately three weeks into the survey period, post hoc power calculations were performed to determine the desired sample size given the 56 responses available at that time. Power calculations for loss of income indicated that a desirable sample size would be greater than or equal to 120 respondents and excellent sample size would be 200 . At the end of the survey period, there were 92 responses in total. This limited our capacity for conclusive hypothesis testing, and so we present descriptive statistics here, as these were sufficient to address the specific research questions posed. Our purpose was to understand the quantitative costs involved, and our sample size fulfils this aim. Future studies would usefully draw on this instrument with a larger sample size to enable finer-grained analysis. Raw results were available in Excel format, which were then loaded into $\mathrm{R}$ for analysis. Thus, our data analysis was based on descriptive statistics gathered on each survey result, which were then aggregated and mean, median and standard deviation derived. Finally, we note that all whistleblowers joined this study by connecting with advocacy, support or legal experts in this field. Negative impacts of whistleblowing are likely to have affected this cohort to a lesser degree than 
whistleblowers without such contacts. Our study may therefore understate the costs of whistleblowing.

We again consulted stakeholders and expert advisors on our emergent findings at whistleblower and stakeholder workshops, e.g. in Belfast, June 2018, and an IWRN conference, June 2019. This post-survey feedback fed into our analysis. Our findings on the intangible costs of whistleblowing largely confirmed extant research (Lennane, 2012; Peters et al., 2011; Jackson et al., 2010; Devine \& Maassarani, 2011; Glazer \& Glazer, 1989; Park et al., 2020). In what follows, we present findings on tangible impacts, focussing on aspects that have to date been under-researched. The emphasis is on quantitative survey findings, with some qualitative responses (provided via open-ended text fields in the survey) used to illustrate key points. We must note that while a feminist lens was deemed most appropriate for analysis of these findings - with extensive justification for this choice provided throughout this article - the survey data could also be interpreted by other ethical approaches or theories such as social and moral identity (see Vadera et al., 2009). However, these would not have produced the insights on material impacts we wanted to unearth.

\section{Results}

Our results detail specific aspects of post-disclosure experiences relating to risk and vulnerability, including income loss, costs and time spent.

\section{Capacity for Future Employment: Blacklisting and Unemployment}

As is typical of whistleblowers, the vast majority of survey respondents had spoken out more than two times to more than one recipient. Participants spoke up about a range of issues from "theft and embezzlement", to "abuse or mistreatment of children". We specifically focused on whistleblowers whose employment status had changed as a result of their disclosure. Among our cohort of 92, 63\% had been dismissed, with $28 \%$ resigning. $62 \%$ had been demoted or allocated a more menial role; in some cases, this happened before dismissal or resignation.

I was in a hostile work environment, my abilities were repeatedly denigrated, my supervisor lied about my performance to those above her in the hierarchy. I was verbally abused, repeatedly threatened with termination. Despite fine recommendations from previous positions, I was told I was incapable of doing my job. A number of my responsibilities were taken away. I was terminated supposedly because I was unable to do my job -a total fabrication. (Female, Disclosed endan- germent of employees (toxic chemicals), Federal/ Government Employee, US)

These kinds of outcomes are not uncommon for organizational whistleblowers (Martin \& Rifkin, 2004).

For those who left their role and spent time out of work, the average duration of unemployment was three and a half years. In addition, respondents reported high levels of blacklisting, that is, formal or informal categorization as an undesirable recruit by potential employers. Of the 77 ( $84 \%$ of total) respondents who gave data on this, $64 \%$ reported formal blacklisting-having encountered written proof, with $21 \%$ informally blacklisted-via word of mouth. A further $29 \%$ had not been blacklisted. Differences across sectors were not significant.

I was constructively dismissed. Prior to this dismissal, it was made abundantly clear to me on innumerable occasions that if I were to persist in reporting the fraud I had discovered it would be the end of all my career prospects. (Male, Disclosed theft/ embezzlement, EU Administration, Belgium)

Blacklisting reduces people's ability to gain meaningful work in their own industry-thus hampering future capacity to earn a salary equivalent to their pre-disclosure remuneration (Devine \& Maassarani, 2011; Eisenstadt \& Pacella, 2018; Glazer \& Glazer, 1989). Changing industry means recasting oneself in a sector for which one has little experience and training, and an accompanying drop in income is typical. This is particularly significant because job performance is strongly correlated with whistleblowing actions; whistleblowers are often high performers with promising careers and, accordingly, have much to lose (Mesmer-Magnus \& Viswesvaran, 2005). Blacklisting significantly decreases the capacity to secure alternative employment and regain one's livelihood if it has been impacted by making a whistleblowing disclosure.

\section{Financial Well-being Post-Disclosure}

\section{Earnings Lost Because of Speaking Out}

To understand more about vulnerability to financial losses on the part of whistleblowers, we examined respondents' earnings differentials resulting from their disclosures. This comprises earnings before speaking up compared to post-disclosure earnings, assessed for each respondent. The result is given as a percentage. An earnings differential measure usefully enables comparison between different overall levels of income and hence different kinds of employments. Of 92 surveyed, 60 people provided information. Of this subset, we found an average drop of $67 \%$ 


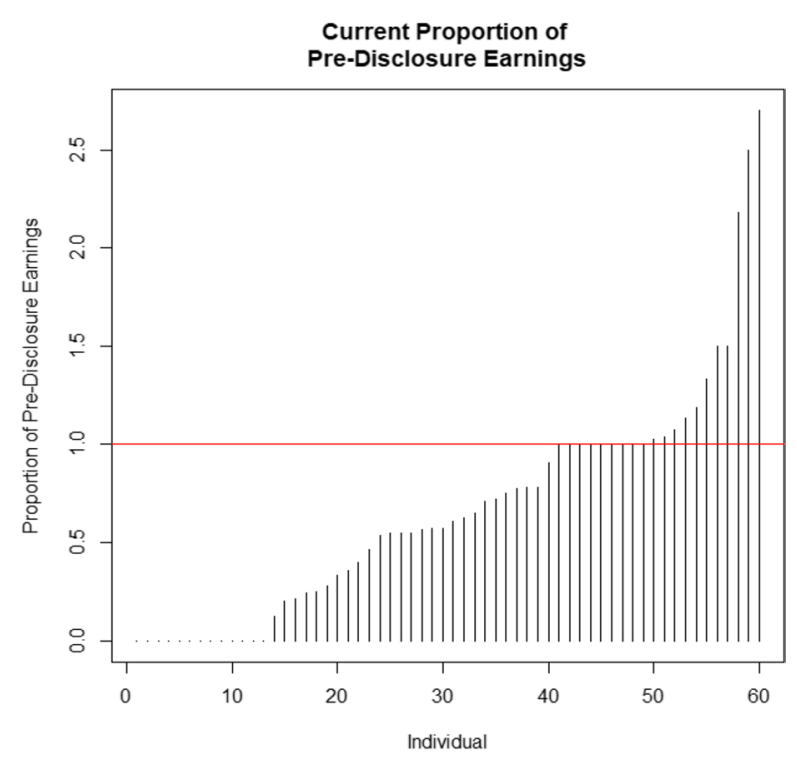

Fig. 1 Change in income as a result of disclosing, for those providing data. (Note: 1.0 represents no change, while 0.5 represents a decrease by 50 percent in earnings)

between earnings pre- and post-disclosure. Forty people (67\%) noted some drop in earnings, while 20 indicated (33\%) that they had not experienced an earnings dip. Of this group, 11 people (18\%) noted an increase in earnings since disclosure (See Fig. 1). This means that speaking out resulted in a loss of income for almost seven out of every ten people who provided data on the difference in their earnings pre and post-disclosure.

Before the disclosure I was on a career fast track and could by now expect to be on a salary of $£ 200,000$.

(Female, Education sector, UK)

Reasons for income reduction include periods of postdisclosure unemployment, career stagnation within the organization as a form of retaliation as above, or having to take a new role with a relatively reduced salary. The latter is common among blacklisted whistleblowers (Kenny, 2019).

My employer's unfair refusal of my application for retention [to stay employed before the case is resolved] has deprived me of five years of earnings at a time when my two daughters aged 16 and 18 are still in full-time education. (Male, Labour Inspector for Government Department, Ireland)

Our findings concerning earnings and the likelihood of dismissal and unemployment provide useful empirical evidence for prior scholarly assertions, which has to date been lacking (Qusqas \& Kleiner, 2001).

\section{Expenses Incurred for Speaking Out}

To gain a clearer overall picture of financial vulnerability, we examined increased outgoings in addition to depleted income. At the same time as earnings dropped, people's costs tended to rise after disclosing. Expenses can be significant and, in some cases, unsustainable. Legal protections for whistleblowers are lacking in many countries (IBA, 2021). Even where they are present, there can be problems in their implementation or gaps in the security and assistance they offer to whistleblowers. In addition, whistleblower laws are often not fit for the purpose intended (Bouloy, 2012). Examples include where cases are dealt with via employment tribunals that place an unfair burden of proof for retaliation on employees, where employers file legal charges against whistleblowers for breach of secrecy and non-disclosure agreements, and where judges, solicitors and lawyers are poorly trained in the nuances of whistleblowing cases (Devine, 2015; Lewis, 2008). These issues emerged as salient for many study respondents. While compensation for detriment, including dismissal, is technically available in many jurisdictions, it can be very difficult to secure. The same is true for financial rewards. In our study, participants found themselves liable for legal costs related to involvement in employment tribunals and court cases. Little help was available to meet these costs.

Focussing on legal costs paid by the whistleblower [Q40-42], forty people provided data on these. While five people or $13 \%$ had spent under $£ 1,000(\$ 1,316)$ in total, a full $25 \%$ or 10 people had spent in excess of $£ 100,000$ $(\$ 131,579)$. 32 people or $32 \%$ had spent $£ 10,000-100,000$.

The corporation did, in fact, intentionally seek to bankrupt me by forcing me to spend on legal fees. I saw that game really quick and knew I couldn't play that game to win. I knew I had to learn to do it myself because I would never have enough money to fight them. I learned quickly and had some wins, but the bottom line is a per-se litigant does not have equal footing in our judicial system to obtain justice. (Male, Manufacturing, US)

An effective legal strategy is an essential part of a successful whistleblowing campaign. As the above response indicates, it can be difficult where whistleblowing cases are complex (see also Kenny, 2019).

It is a scandal that the EU's Court of Justice does not award legitimate legal costs relating to pre-litigation and essential legal advice. I have spent my life savings on my legal defense. (Male, Disclosed theft/ embezzlement, EU administration, Belgium)

We tested for differences between countries in terms of legal costs reported and did not find significance. We note 
that 48 people described having part of their legal fees waived by lawyers, paid by a union or receiving assistance from a whistleblower support group, but that costs were significant, nonetheless.

Our findings indicate that adverse health effects, both mental and physical, were experienced by two-thirds of our cohort [Q47-52]. 65\% of our respondents experienced negative changes to mental health (either 'worse' or 'much worse'), attributing the change to their disclosure activities. We focused on the cost implications for those reporting negative changes, finding that disclosures often gave rise to increased health care costs [Q49]. The average cost of support for mental health problems was $£ 1,036 / \$ 1,480$ per year (the approximate mode for expenditures of this kind was $£ 1,000 / \$ 1,316$ per annum). Counselling is of course, not always an option:

There is no money to treat mental health so it goes untreated. (Male, Disclosed fraudulent/ predatory financial practices, Manufacturing, US)

Meanwhile, costs for physical health issues related to one's disclosure ran to an average of $£ 1,126 / \$ 1,609$ per year. This provides empirical support to observations made in earlier studies focused on the health impacts of whistleblower retaliation but not the costs (Lennane, 2012; Cortina and Magely 2003). Reduced financial security resulting from disclosure can have additional impacts, including increased interest rates and loss of credit, which further add to the cost of health care.

Lost credit and pay a premium in interest; have ongoing medical bills that cost $\$ 500$. Per month in payments for past medical costs. (Female/ Government/ breach of policy, US)

Twenty-nine people (32\% of respondents) reported attempts to retrain or seek further education to recreate career opportunities. Such activities also incurred costs, the average being $£ 16,035$ (\$21,099), excluding one large outlier. Four respondents opted for early retirement instead of retraining. Other hidden costs of disclosure involve seeking assistance from whistleblower advocacy and support groups including legal advice and attending peer support meetings. People reported costs of approximately $£ 2,000(\$ 2,632)$ in total per person (this mode value is the most representative measure because of a small number of extreme outliers in this category that skewed the average cost).

Difficult to calculate - I estimate an average of 8 hours a month (at least) from June of 2004 until settlement in the fall of 2006. Not counting the cost in time, money, and anxiety for a round-trip flight from D.C. to Denver for depositions. (Female/ Federal government/ excessive waste, US)

Overall, we find that costs relating to legal cases, health care and support-group access can increase. Stress and related mental health impacts are prevalent among whistleblowers but obtaining adequate psychological support is expensive when accessed privately, while public access to quality mental health care is often limited. Moreover, counsellors who are experienced in dealing with the specific challenges involved in whistleblowing disclosures are scarce.

\section{Speaking Out: The Price Tag}

For each individual providing relevant data, we combined income loss with information on new and unexpected expenses incurred. We multiplied yearly lost earnings by the number of years since the disclosure, adding this figure to total physical health cost, plus mental health cost, lost retirement benefit, advocacy meeting costs and total legal fees. Our respondents varied in the length of time since they disclosed; hence, these data are presented as a yearly average. Shortfalls averaged $£ 24,817(\$ 32,580)$ per annum. Isolating those whistleblowers who experienced a depletion of their earnings, their annual shortfall ran to $£ 58,114$ $(\$ 76,291)$. We compared data between geographic locations and employment sectors, finding no significant differences. A breakdown of these data sees 21 respondents (23\%) with a shortfall of over $£ 50,000(\$ 65,790)$ per annum, while 10 respondents $(11 \%)$ note a discrepancy of over $£ 100,000$ $(\$ 131,579)$ per annum. Our survey responses to Q37, 39 and 42 provide background context to help us understand these figures:

I did not plan on retiring and spent everything to survive the health and financial losses with both, an interruption in pay for six months in 2012 and removal... in 2013. I was left with no choice but to spend whatever I had to pay cost of loss of my home and move from that home that I could not pay for. I have rebuilt my health but can hardly make ends meet month to month but continue to try by freelancing in work. (Female, Disclosed serious policy breaches, Federal/ Central Government, US)

The reduction in the financial safety net was a common theme, with buffers against fiscal precarity including savings for retirement depleted:

A reduction in all of my spending. I had to live on my savings which substantially impacted on the amount of funding I have to live on and for my retirement. (Female, Health, US) 
While our survey responses were too few and too diverse to estimate the loss of retirement benefits as a portion of the expected total, $50 \%$ reported at least some loss in retirement benefits and/or pension entitlements. Some who were terminated following disclosure described losing employer matching funds. At least one respondent cashed in pension benefits for living expenses following termination of employment.

In addition to retirement savings, some reported loss of basic things required to protect against future precarity, including insurance and repairs:

I can't afford to go out and do anything anymore. All my money goes into bills. Had to put off home and vehicle repairs and health insurance. (Female/ Fed/ gov, excessive waste or mismanagement, US)

People noted how income reduction can have exponential impacts on families, given the number of dependents involved:

Losing \$12,000 a year affects everything for a family of five. (Male, Education, US, Cronyism/ nepotism)

Overall, we see that the financial impacts of speaking out can be complex. A reduction in one area can have significant knock-on effects in others, and impacts on family members.

\section{Time Costs of Speaking Out}

Time spent on one's disclosure is an indirect cost of speaking out Time costs have received little attention in research studies to date. Whistleblowers often spend months and indeed years on their disclosures. Seeking justice for related detriment can become a second campaign requiring as much cost and effort as the original whistleblowing claim. In both cases, time is spent preparing for, and engaging in, oftenlengthy court cases: compiling evidence, researching legal rights, studying organizational policies, assisting investigations, and sometimes advocating for political and public support.

From my dismissal in 2000 until after I filed with Federal Circuit in Sep 2003, I had no formal legal representation. I did everything on my own with some guidance from one not for profit attorney. I spent at least 2000 hours over the nine years of battle to settlement. (Female, Disclosed contractor corruption, Federal/ Central Government, US)

We enquired into the amount of time spent by people [Q43] and found 2 people (3\%) reporting less than 100 hours (h) on disclosure-related activities. Thirty-five people (57\%) spent $100-1000 \mathrm{~h} ; 22$ (36\%) people spent $1000-10,000 \mathrm{~h}$, while 2 people spent in excess of $10,000 \mathrm{~h}(3 \%)$. To put these figures in context, the average (full-time) working person spends $1700 \mathrm{~h}$ on their job per year; one in three whistleblowers in our study spend close to this figure on their disclosures. There is often no option but to become familiar with complex legal terminology. This time is often necessary because only the whistleblower has the knowledge and experience to provide lengthy and detailed descriptions of the wrongdoing and any subsequent retaliation. Such work is often carried out alone, unsupported and unpaid.

16,768 [hours spent on disclosure]. This is on an average of two days a week over eight years-[I am a] self-represented litigant (After paying legal costs, the discovery of documents and other, preparing bundles and legal submissions, correspondence, researching the law). (Female, Disclosed abuse/ mistreatment of children, Education, UK)

Negative impacts of disclosure on one's mental and physical health can prolong the time and effort required, as can the depletion of financial resources and capacity to pay for assistance. Hence the cumulative material impacts of speaking out are clear.

Time is also spent seeking help from journalists, politicians, regulators and lawyers, all of whom require different presentations of case information. Whistleblowers can be subject to attacks as a result of press coverage and on social media. Meanwhile, both forums represent a powerful means of presenting one's case in a positive way, acting as a catalyst for whistleblower support and legal reform (Devine and Maasarani 2011). For a whistleblower whose name has been made public, these activities are not optional but are an essential aspect of successful whistleblowing, and of personal survival (Culiberg and Mihelič 2016; Kenny, 2019; Martin, 2014). Advocacy assistance can help garner positive responses from members of the public, professional validation for the whistleblower and help shed light on the wrongdoing reported (Smith \& Brown, 2008).

This under-acknowledged time burden has material impacts upon a whistleblower's capacity to secure bodily safety and well-being. This time spent on disclosures might otherwise be devoted to seeking further employment, retraining and in some cases engaging in the self-care required to mitigate the adverse health effects of whistleblowingrelated stress. Time represents a cost that is often hidden and rarely discussed in this context. While some scholars have described the impact of time on whistleblower struggles, they typically focus on the period spent disclosing internally through an organization's prescribed channels (e.g. Vandekerckhove \& Phillips, 2019), or on descriptive accounts of the activities involved (Roulet, 2020). 


\section{Benefits of Speaking Out}

Prompted by our advisory team, we asked people about personal and social benefits from their disclosures [Q53, 54]. Concerning personal benefits, the overwhelming majority (71\%) of respondents said they experienced peace of mind as a result of speaking out, with $62 \%$ expressing satisfaction that they had raised awareness of the wrongdoing issue.

It was a strong success because, including in the culture, our experience was put in [a] theatre play. Many people realise they have the same story of life with us...so it was inspirational for many people. (Male, Romania, construction, corruption)

When asked about personal benefits gained from speaking out, $50 \%$ described helping others, while $38 \%$ cited acquiring new friends and connections. Of the first group, $89 \%$ of respondents reported some benefit to others from their disclosure, which ranged from raising awareness to empowering other whistleblowers (Table 1).

I became a national voice trying to better the care for Veterans across the United States as well as speaking for whistleblowers that no one ever heard of. (Male/ US/ Fed gov/ Patient safety)

Thus, the experience of disclosure was not only negative. The more positive aspects of speaking out, including opportunities for internal growth and involvement in more meaningful pursuits than one's previous job (referred to by some people working in finance, for instance), are often overlooked; hence these findings help paint a richer picture of people's experiences. It is important to note that we do not suggest that these intangible benefits can somehow offset

Table 1 Responses to questions: 'Please identify any of the following personal/social benefits you have experienced as a result of your disclosure'

\begin{tabular}{ll}
\hline Personal benefit experienced as a result of disclosure & Percentage \\
\hline Peace of mind & 71 \\
New friends and connections & 38 \\
Helped others & 50 \\
Positive career change & 17 \\
No personal benefits & 6 \\
Social benefit experienced as a result of disclosure & \\
Raised awareness & 62 \\
Improved public safety & 26 \\
Saved taxpayer money & 17 \\
Empowered other whistleblowers & 40 \\
No social benefits & 11 \\
\hline
\end{tabular}

the impacts of speaking out, nor be 'deducted' from the costs of speaking out.

As we see overall, the aftermath of whistleblowing can be expensive. Earnings can go down just as costs are increasing, leading to shortfalls in income. The time required to work on one's whistleblowing disclosure can be significant. Our quantitative findings highlight the extent of this. Our results depict how the tangible impacts of speaking out, including financial and temporal, can be experienced alongside intangible impacts, including low self-esteem and increased stress. These impacts are, we suggest, mutually constitutive. Different measures can cumulatively affect each other. Depleted finances can mean increased interest rates for inevitable borrowing. Necessary new spending on health care can require moving to a different home, with the disruption this brings. Time spent on disclosures can not be devoted to seeking further employment to secure new sources of income and pay expenses. It is also time taken away from social and family life, which exacerbates anxiety. Meanwhile, stress can deplete the ability of whistleblowers to seek gainful employment and the strength to carry on fighting their cause. At the same time, unemployment can further aggravate the negative impacts of disclosure, and result in a reduced ability to pay for supports. These cumulative impacts are hinted at in qualitative accounts of the negative impacts of whistleblowing, but until now, empirical data on costs are rare.

\section{Discussion}

Our data are unique because it represents one of the first attempts to effectively quantify the costs of speaking out. Discussing our findings, we build upon extant research by illustrating important material aspects of a vicious cycle of tangible and intangible impacts. We see how the costs of speaking up can affect the bodily experience of post-disclosure survival. The cost of shifting from a secure position within the 'norm' of the organization as a trusted employee to this new position, outside the norm, potentially in dispute with the organization and compelled into a new kind of time-consuming labour aimed at securing one's existence, is a cost that is experienced by the body, endangering the whistleblower and exposing her and her family to risk and precarity. Analysing our findings, we propose a new conception of post-disclosure experience, focussing on the materiality of the body and inspired by Judith Butler's recent work. Rather than assuming an a-priori ethical duty to speak out, we look into its consequences for whistleblowers themselves. Offering novel vistas on the embodied labour of whistleblowing during and after disclosure, these ideas add to extant debates on the material actualities of whistleblowers' experiences. Theoretical frameworks focusing on 
the social and political significance of their actions rarely address these issues.

Our contribution is twofold. First, we explicate an aspect rarely acknowledged in the whistleblowing research concerned with the negative impacts of retaliation by organizations and having one's name made public. In how these impacts are framed, there is insufficient consideration given to the issue of materiality and consequences on the body (e.g. via time, finance and other costs). Our study found that the aspects of life that enable bodily survival, including income, time, supports for health care, and social and institutional supports, can be diminished, sometimes significantly. The impacts can be insidious and not easily visible from the outset, not least because of the cumulative and intersectional way they can affect both whistleblowers and their familiestheir capacity to live decent lives and continue their whistleblowing journeys. Extant studies describe the experience of the whistleblower who finds him or herself outside the norms of organizations and the intangible impacts on those who leave their role as a result of speaking out, including isolation, pain and stress (Alford, 2001; Kenny, 2018; Mesmer-Magnus \& Viswesvaran, 2005; Miethe, 1999). Building on existing knowledge, our study shows that to be labelled 'whistleblower' can also have clear material implications for the person who comes to be known by this name, and their dependents, thus adding to understandings of post-disclosure experiences.

This is important to acknowledge because extant research approaches in business ethics appear to emphasize the individuality of the whistleblower, alongside an implied disconnectedness from the body and others. Calls in business ethics and policy circles, for increased responsibilization of employees for ethical disclosures-underscored by an idea of duty-compel people to come forward. This, however, suggests an anaemic understanding of the risks of disclosure for the whistleblower. Current approaches effectively support the status quo in which whistleblowers struggle. Little is done to help them while ignoring or downplaying the perils and consequences of whistleblowing exacerbates the risk for this group. Turning to our findings, it is vital to call into question this view of the self as singular and independent of others. In making this point, it is critical to emphasize that we are all constitutively dispossessed and vulnerable as subjects because of our dependence on others for social recognition but also because of our bodily injurability (Butler \& Athanasiou, 2013). However, these dynamics are particularly salient in the case of whistleblowers because they risk further exclusion from the social domain of intelligibility. Whistleblowers, as is well-established, can find themselves placed outside of organizational norms because their disclosures pose a threat and outside of social norms due to stigmatization (Alford, 2001, 2007; Kenny, 2019; Van Portfliet, 2020). These symbolic exclusions and attacks on their integrity lead to tangible adverse impacts; thus, speaking up can be accompanied by progressive and severe material deprivation, as our research highlights. The case of whistleblowers being positioned on the outside of social norms also demonstrates how the impacts of speaking out depend on the material conditions in which people find themselves, and determine whose lives are deemed worthy in a given context (Butler, 2016). It also shows that when individuals question dominant social norms, even dubious and corrupt ones, they risk positioning themselves outside the category of worthy lives that merit protection (Kenny, 2018). Taken together, this has important implications for the study of whistleblowing as an ethical obligation on the part of the employee because it provides valuable insight into the extent and nature of the risks involved. Specifically, it challenges positions that hold whistleblowing as an ethical duty. Our concern is that to reproduce this concept when we think about enfleshed subjects who care for others and/or the common good - such as whistleblowers for instance-is to misunderstand both their acts and, crucially, the implications of these acts for themselves and others that depend on them.

Our second contribution is to show that 'whistleblower' is more than a label. The position gives rise to new forms of work required to sustain the body, even as the material conditions enabling this sustenance erode. Our data show that significant time investments and material and affective work are often needed to disclose wrongdoing and to survive the experience. Yet, this aspect is rarely seen as the work activity it is. Specifically, for those who leave their role as a result of disclosing wrongdoing, the activity of whistleblowing, post-disclosure, can be reframed as a fulltime, all-consuming job, in and of itself. This can take different forms depending on the circumstances. In some cases, when a whistleblowing claim continues for a long time and involves persistent blacklisting or a likely smear campaign (Eisenstadt \& Pacella, 2018), the situation also requires a shift into an advocacy role for oneself alongside the forging of a new career. In other cases, the mere work of disclosure is complex and time-consuming in and of itself. To date, this aspect has been overlooked in research. We reframe whistleblowing as a form of labour aimed at defending against precarity. Whistleblowing can be an activity requiring effort and time, that must be carried out to ensure survival, and that as yet remains unpaid and unsupported.

This gives rise to the question of how to view this 'labour of whistleblowing'. Here, it appears that intersubjective interdependency is at the core of post-disclosure survival. Our research highlights the necessity for connection with others, for example, whistleblowing support groups, media and other whistleblowers. Moreover, in response to questions about what personal benefits were gained from speaking out, people overwhelmingly cited their ability to help others: in nine out of ten responses (Table 1). A re-reading 
of extant studies shows the intersubjective interdependency that characterizes many whistleblowers' motivation to speak out against various forms of wrongdoing. One manifestation of this is the desire to help others, and the pleasure experienced when this is achieved (see Alford, 2001; Van Portfliet, 2020). Equally, this interdependency is evidenced in people's post-disclosure experience during which they require support from various parties, support that can be difficult to secure. In short, the other is at the centre of people's whistleblowing experiences.

To date, arguments around whistleblower protection have prioritized the autonomy of the individual whistleblower, for example, arguing for her legal rights or organizational status to be upheld and emphasized (Kenny et al., 2020). Of course, this is vital - and to be welcomed. However, because this perspective stops at the boundary of the body, it ignores the interconnections the body inevitably holds. It sees bodies-including whistleblower bodies-as discrete, singular entities and fails to capture their dependencies on others, as well as their corporeal vulnerability. Our findings point towards the inextricable sociality of whistleblowing experiences, which suggests the need for new kinds of support infrastructures to resist the material plight of whistleblowers (see also Munro, 2017). Thus, we argue here for infrastructures of whistleblower support based on an alternative perception of the body, which is more appropriate for this setting, as we have shown. Suppose, our concern is helping whistleblowers in precarious bodily circumstances. In that case, we must acknowledge that at the heart of "what a body is... is its dependency on other bodies and networks of support". Along with practical and material forms of support, therefore, discursive and symbolic support is also needed because the relationality of the body includes "dependency on infrastructural conditions and legacies of discourse and institutional power that precede and condition our existence" (Butler, 2016: 21).

Reframing the labour of whistleblowing in this way speaks to literature perceiving disclosure as a form of resistance to organizational domination (Contu, 2014; Rothschild $\&$ Miethe, 1999). Extant literature has described the potential for whistleblowers to effect political change by occupying positions of "truth-teller" to oppose domination (Contu, 2014; Kenny et al., 2020; Rothschild \& Miethe, 1999; Weiskopf \& Tobias-Miersch, 2016). Whistleblowers can, in some cases, lay new claims to the term 'whistleblower' that parody and reframe its traditional, negative associations and enable more liveable modes of existence under its terms (Kenny, 2019). While such work is valuable, we note that the mechanics of such opposition-and the conditions of possibility for their emergence-are not given much attention in the literature. We share the optimism that whistleblowing can effect positive change-indeed, we have observed such instances-but we note that even where this occurs, the impact on the whistleblower herself is often far from positive. However, recognition is not enough if we are to mitigate these negative impacts. A focus on materiality and relationality is vital. Moreover, a "supportive environment and set of technologies" is required that enables those who speak truth to power to "exercise most basic rights" (Butler, 2016, p. 15) before we can even consider their capacity to engage in meaningful resistance. In their absence, the ability to resist is dramatically reduced. For this reason, the discursive focus that emphasizes a whistleblower as the "subject of norms", but a somewhat disembodied one, has not gone far enough.

We return to our original questions around the ethical obligation of the whistleblower imposed upon her by society. We perceive that the political meaning of the humanincluding that of the whistleblower-can only be understood by paying attention to the relations that are essential for her bodily survival (Butler, 2016, p. 16). We have shown how whistleblowers can exhibit bodily precarity and vulnerability post-disclosure. We argue that we cannot conceive of whistleblowers' post-disclosure survival, outside of this renewed conception of the social and material relations to which they are inextricably embedded. Drawing on the feminist ideal of the mutual vulnerability of embodied subjects enables us to go further. The proposed concept of embodied relationality offers a way to reconsider our engagement in the private and public spheres through the prism of the body's vulnerability we all share (Kenny \& Fotaki, 2015). Specifically, we can extend these social and material relations to the dependency of ordinary members of society on whistleblowers who speak out in the public interest and have done so on numerous occasions in the past. Reversing typical formulations in business ethics, we turn extant debates on the ethical duty of whistleblowers on their head and propose acknowledgement of reciprocal exposure and vulnerability shared between whistleblowers and those upon whose behalf they speak (cf Cavarero, 2007). Mandating such duty is unreasonable where risk is extensive, and this is the case currently. Moreover, we perceive a distinct ethical duty on the part of society and its institutions to provide and maintain the infrastructures of support that enable the survival of those who would speak truth to power on behalf of us all. If we accept that whistleblowers' dispossession extends to the material as well as symbolic dimensions, this puts a certain obligation on society for whistleblower protection. Our theoretical contributions thus yield important practical implications, which derive from our foregoing analysis.

\section{Rethinking Supports}

Overall, there is little information on the financial impacts and costs of whistleblowing upon which to develop appropriate supports. As a result, organizations suffer from an 
inability to address wrongdoing and malpractice early on and thus avoid disasters and protracted legal battles (European Commission). But the problem with this approach failing to specify material consequences of speaking up for whistleblowers goes beyond organizations; an absence of meaningful financial supports effectively upholds ongoing wrongdoing that could negatively affect the safety and wellbeing of citizens around the world. The proposed legislation includes calls for national governments to ensure whistleblower support is available post-disclosure and to consider how best to provide appropriate financial assistance (e.g. EU Commission, 2018). However, this shift in policy is not matched by robust underlying empirical evidence that might shape practice, while our findings highlight the inadequacy of the status quo across jurisdictions. Based on our analysis, how can we rethink supports for whistleblowers who find themselves financially impacted so that their quality of life and that of their families are not adversely affected? How might organizations play a key role in enabling survival and supporting them against vulnerability in precarious situations? (Tyler, 2019). Our research suggests two practical implications for the provision of assistance.

First, activities relating to legal issues and advocacy work including media, political and other forms, cost either time or money, as we have demonstrated. Whistleblowers are generally not trained in these areas, exacerbating both time and financial costs. Providing access to expertise would help with expenses and free up time. We recommend expert, supported, assistance for whistleblowers dealing with legal professionals, media outlets and political representatives. For example, some advocacy groups provide useful 'matchmaking' connections between lawyers, whistleblowers and journalists, supplying advice guides for all involved (Government Accountability Project, 2017), albeit such schemes are rare. Providing mental and physical health support is equally critical. Emergent whistleblowing protection laws indicate the provision of support as a priority but are vague on the specifics (European Commission, 2018). Our analysis suggests the form this might take.

Second, current financial supports are grossly inadequate. People can suffer financial detriment that has an ongoing impact on their working lives and beyond. Current schemes to help whistleblowers with financial detriment suffer because laws are weak, and legal loopholes abound (Devine, 2015). Compensation for retaliation comprises a maximum of five times one's annual salary and is often much less, a figure that does little to mitigate long-term financial effects and is anyway difficult to secure given legal obstacles. Rewards and bounties help a minuscule percentage of those who require help in this area. The result is that whistleblowers and their families are typically left to shoulder financial burdens unassisted. Legal reform is required, as others are advocating (Eisenstadt \& Pacella, 2018). While waiting for this reform, financial legal aid is vital to help whistleblowers negotiate a difficult landscape, and this is lacking in many jurisdictions. Interim relief funds are essential given the lengthy periods between disclosure and resolution of one's legal case. It appears important to extend such support beyond the phase of disclosure where this is required.

In the absence of these infrastructures, we note that the cost of whistleblowing can deter people from continuing their struggle; aggregate effects become too great, and they simply run out of the money and the will necessary to fight their battles alone. The result of cumulative pressure is that the temptation to accept a settlement with a retaliating organization or abandon the struggle outright is very strong and increases as resources deplete (Kenny, 2019). That these impacts have not been addressed in research or, largely, in policy to date suggests that the position of the whistleblower is not valued in today's society. We hope that this study goes some way to rectifying this.

Even so, following feminist theorists on this topic, we do not propose that somehow, once and for all, we might overcome the vulnerability experienced by whistleblowers. Structures of oppression and domination endure, as do attempts to speak truth to power on behalf of those who suffer. Instead, we aim to make the conditions of engagement: the landscape and ground upon which whistleblowers are often forced - unwilling - to make their disclosures, "more just, more equal, and more enabling" (Butler, 2016, p. 19). We hope to do so by providing appropriate support and thus ameliorating the risks for those aiming to protect the public interest (Tsahuridu and Vandekerckhove 2008). This study represents a partial glimpse into the broader question of how we understand whistleblowers' experiences post-disclosure and how we might best support this group. Future research will hopefully focus on the particular kinds of career redevelopment paths taken by whistleblowers who have left their role, something we have begun (Fotaki \& Kenny, 2019; Kenny \& Fotaki, 2019). Studies that involve participants keeping time diaries to generate more accurate results for time spent will be helpful to build upon our survey data based on their recall; further research would be useful in this area. A second area meriting investigation is the impact of post-disclosure survival activities, including the time-consuming project of alliance-building with supportive others, on the whistleblower's immediate dependents including family members. The role of the various 'others' dependent on the whistleblower and upon whom she depends for survival is under-researched. Finally, just as different country and cultural contexts require more detailed investigation, as noted above, it will be important to study gender dimensions, which, as others have shown combine with relative power within society to affect whistleblowing experiences (Rehg et al., 2008). This focus is critical, not least given the importance of care relations for whistleblower survival. 


\section{Conclusion}

Our study aimed to address a persistent ambivalence in societal attitudes towards whistleblowers. On the one hand, we depend on their disclosures to protect the public from major health and environmental fallouts, financial loss due to wrongdoing and corruption and failing governance. On the other hand, we do not offer sufficient protection and support for those who do this on our behalf. The absence of financial or other supports, for people who sacrifice so much for our safety, indicates a lack of understanding of what it takes to speak up and its real-life implications. Despite some calls for change, there is little evidence of this paradox being resolved. Whistleblowing can come with a hefty price tag. Our findings suggest that the public debate on whistleblowing needs to be changed to recognize whistleblowers' bodily vulnerability and to support them accordingly. We recommend that a deeper understanding, theoretically and empirically, of the costs whistleblowers face due to their bravery will provide a first step in this direction.

\section{Appendix 1}

\section{The Survey}

In this survey, we are seeking information from people who have spoken out in their organizations and are no longer in their former role as a result of their disclosure, either through resigning, moving positions internally or having been dismissed. Currently, there is no detailed research into this area and so your response will be part of one of the first efforts to quantify the costs to whistleblowers. We will send you a report on the findings of this research project.

\section{Personal and Work History Information}

The following questions concern your personal and employment history. If you feel that any of these questions do not apply to you, you may leave them blank and proceed to the next question.

1. Choose your currency

GBP
EUR
USD
Other (please specify)

2. What sector were you working in at the time of your disclosure?

[Menu]

Other (please specify)

3. Gender

Female

Male

Other (please specify)

4. Current age

5. Age at time of disclosure

6 . What was your country and city or region when you disclosed?

Country

City or Region

7. How long had you been in your organization at the time of your disclosure?

Years

Months

8. Which best describes your position at the time of your disclosure?

Professional or skilled (doctor, chef, engineer, financial professional)

Unskilled (carer, waiter, labourer)

Director, Executive or Manager

Scientist or researcher

Administrative or clerical

Other (please specify)

9. How long had you been in your specific role at the time of your disclosure?

Years.

Months.

\section{Information About Your Disclosure}

The following questions concern your disclosure. If you believe that any of these questions do not apply to you, you may leave them blank and proceed to the next question.

10. Please select the category that best describes type of wrongdoing that you disclosed 
Endangerment of employees

Endangerment of the public

Cronyism or nepotism

Theft or embezzlement

Sexual violence, misconduct or harassment

Excessive waste or mismanagement

Patient safety

Discrimination

Manipulation, censorship or disregard of research findings

Breach of confidentiality

Breach of organization policy

National security and intelligence mismanagement

Corporate information security

Abuse or mistreatment of children

Fraudulent or predatory financial practices

Other (please specify)

11. Please provide a brief description of the type of wrongdoing that you disclosed.

12. Which best describes your personal association with the wrongdoing?

No involvement, wrongdoing outside of role in organization

No involvement, wrongdoing was within role in organization

Some involvement, wrongdoing was outside role in organization

Some involvement, wrongdoing was within role in organization

Other (please specify)

13. Who was primarily harmed by the wrongdoing?

People outside the organization

People inside the organization, including yourself

People inside the organization, not including yourself

People inside and outside the organization

Other (please specify)

14. How often did this wrongdoing occur?

Once

Multiple Times

15. What was the duration of the wrongdoing?

Less than one month

One to six months

Six months to two years

Two to five years

Longer than five years
16. How would you describe the wrongdoer's power in the organization relative to your own?

More powerful

About the same

Less powerful

17. How many times did you raise your concern?

Once

Twice

Three times

Four or more times

18. With which party did you first raise your concern?

Wrongdoer
Manager in your organization
Grievance procedure in your organization
Union
Regulator outside your organization
Police
Media
NGO
Government representative
Other (please specify)

19. If you raised your concern multiple times, please tick every party with which you raised it.

\author{
Wrongdoer \\ Manager in your organization \\ Grievance procedure manager in your organization \\ Union \\ Regulator outside your organization \\ Police \\ Media \\ $\mathrm{NGO}$ \\ Government representative \\ Other (please specify)
}

\section{The Organization's Response to Your Disclosure}

The questions in this section concern your organization's response to your disclosure. If you believe that any of the questions do not apply to you, you may leave them blank. We would like to remind you that your responses will be fully anonymized, and you may contact us if you have any questions.

20. Were you dismissed as a result of your disclosure? 
Yes

No

21. Were you demoted or given a more menial role as a result of your disclosure?

Yes

No

22. Did you experience reprisal other than demotion or dismissal as a result of your disclosure?

Examples could include discipline, corrective action, poor performance evaluation, change in pay, benefits or awards, change in working conditions, threats, verbal or physical harassment, etc.

$$
\begin{aligned}
& \text { Yes } \\
& \text { No } \\
& \text { If yes, please describe. }
\end{aligned}
$$

23. Did you leave your organization voluntarily?

Yes

No

24. If you left your organization voluntarily, was this the result of your disclosure?

Yes

No,

Please give a brief description of the circumstances.

\section{Income and Earnings}

The questions in this section concern income and earnings as they relate to your disclosure. If you believe that any of the questions do not apply to you, you may leave them blank and proceed to the next question.

25 . How much time has passed since you left your original role?

Years

Months

26. Did you spend a period of time without employment income after leaving your previous role?

Yes

No

If yes, how long?
27. Have you been blacklisted in your industry or sector?

No

Yes, formally (you have encountered written proof)

Yes, informally (you have had verbal evidence)

28. Are you currently employed full time?

Yes

No

29. What were your annual before-tax earnings in the following categories prior to your disclosure?
Salary
Dividends from stocks
Interest earnings
Health benefits and insurance
Car or other transit allowance
Bonuses
Other (specify)

30. Which best describes your role as an earner in your household prior to disclosure?
Sole earner
Primary earner
Secondary earner
Equal earner with partner or spouse

31. What are your before-tax annual earnings in each of the following categories in your current role?
Salary
Dividends from stocks
Interest Earnings
Health benefits and insurance
Car or other transit allowance
Bonuses
Other (please specify)

32. Following disclosure, which best describes your role as an income earner in your household?
Sole earner
Primary earner
Secondary earner
Equal earner with partner or spouse
Not currently earning

33. Have your promotion prospects been curtailed as a result of your disclosure? 
Yes

No

If yes, please describe how your prospects have changed.

34. Have you forgone pension entitlements having left your role?

Yes

No

If yes, please estimate the amount and specify if this is gross or annual.

\section{Response to Changes in Income}

The following questions concern your responses to changes in income resulting from your disclosure. If you have not experienced a loss of income as a result of your disclosure, please indicate this in question 34 , then proceed to question 37 .

35. If you did not experience a loss of income or reduction in spending, please tick the box below and proceed to question 37 .

I did not experience a loss of income or reduction in spending

36. Please estimate your reduction in spending in each of the following areas per month

Housing

Food, clothing, transportation

Education (for self, family)

Recreation and travel

Savings

Other (please describe)

37. Please give any additional comments regarding reduction in spending here.

38. Please estimate the total amount you have received for each of the following means of compensation for lost income

Sale of property or assets

Loans from family or friends

Compensation from employment tribunal or court case

Compensation from whistleblower reward scheme

Settlement with organization as a result of disclosure

Redundancy payment

State assistance

Legal fee assistance as included in home insurance
Other (please give details as appropriate)

39. Please give any additional comments regarding compensation for lost income here.

\section{Costs Resulting from Your Disclosure}

40. Please estimate the total amount you have spent on the following legal expenses to date.
Brief
Consultation
Drafting
Trial costs
Negotiation
Other legal expenses

41. Has your lawyer or solicitor waived any of the fees above? Please indicate the amount.

42. Please give any additional comments regarding legal expenses here.

43. Please estimate the time you have spent working on your disclosure in your free (non-work) time in hours and include any additional comments.

44. Please estimate the amount you have spent on education and retraining costs, and include any additional comments.

45. Please estimate the amount you have spent on transportation, subsistence and accommodation for advocacy group meetings, and include any additional comments. 46. Were you ordered to pay the legal costs of your former employer in circumstances where you were unsuccessful in your legal claim? Please indicate the amount.

\section{Health and Personal Consequences}

47. Which best describes your physical health post-disclosure as compared to pre-disclosure?
Much better
Better
The same
Worse
Much worse

48. If there have been changes in your physical health, to what extent do you believe they are related to your disclosure? 
Strongly related

Somewhat related

Not at all related

49. Please estimate what you have spent on the following items.

Health care costs out of pocket

Health care costs covered by insurance or national health scheme

Transportation, subsistence and accommodation relating to medical visits

Other health expenses (please describe)

50. Which of the following best describes your mental well-being post-disclosure as compared to pre-disclosure?

\section{Much better \\ Better \\ The same \\ Worse \\ Much worse}

51. Please estimate what you have spent on mental health supports

52. If there have been changes to your mental well-being, to what extent do you believe they are related to your disclosure?

\section{Strongly related}

Somewhat related

Not at all related

53. Please identify any of the following personal benefits you have experienced as a result of your disclosure

Peace of mind for having spoken out

New friendships and connections

Positive change in career

Helped other potential whistleblowers

Other (please specify)

54. Please identify any of the following social benefits you believe have come from your disclosure

Raised awareness of an issue, inside or outside your organization

Costs saved to the taxpayer (please estimate below)

Improved public safety

Empowered or inspired other whistleblowers to come forward

Other benefits to society (please describe below)
Other (please specify)

Thank you

We appreciate very much the time you have taken to fill this out. We are aware of the sensitive nature of these data and so our survey is anonymized; your name or email address will not be linked in any way to your answers, as per our Universities' ethics protocol, described below.

Your response will help us to ascertain the loss that whistleblowers experience which is not only in terms of career and personal impacts but also financial and practical.

We look forward to sharing our results with you.

Thanking you

[authors]

Acknowledgements This research was funded by the Economic and Social Research Council UK, Grant No. ES/N007085/1. We would like to thank postdoctoral research assistant Dr Alexis Bushnell.

\section{Declarations}

Conflict of interest Kate Kenny and Marianna Fotaki declare that they have no conflict of interest.

Open Access This article is licensed under a Creative Commons Attribution 4.0 International License, which permits use, sharing, adaptation, distribution and reproduction in any medium or format, as long as you give appropriate credit to the original author(s) and the source, provide a link to the Creative Commons licence, and indicate if changes were made. The images or other third party material in this article are included in the article's Creative Commons licence, unless indicated otherwise in a credit line to the material. If material is not included in the article's Creative Commons licence and your intended use is not permitted by statutory regulation or exceeds the permitted use, you will need to obtain permission directly from the copyright holder. To view a copy of this licence, visit http://creativecommons.org/licenses/by/4.0/.

\section{References}

ACFE. (2018). Report to the nations on occupational fraud and abuse: 2014 global fraud study. Association of Certified Fraud Examiners.

Alford, C. F. (2001). Whistleblowers: Broken lives and organizational power. Cornell University Press.

Alford, F. (2007). Whistle-blower narratives: The experience of choiceless choice. Social Research, 74(1), 223-248.

Antoni, A., Reinecke, J., \& Fotaki, M. (2020). Caring or not caring for coworkers? An empirical exploration of the dilemma of care allocation in the workplace. Business Ethics Quarterly, 30(4), 447-485. https://doi.org/10.1017/beq.2020.1.

APPG. (2020). Making whistleblowing work for society. All Party Parliamentary Group on Whistleblowing.

Bjørkelo, B. (2013). Workplace bullying after whistleblowing: Future research and Implications. Journal of Managerial Psychology, 28(3), 306-323.

Bouloy, K. (2012). The Public Interest Disclosure Act 1998: Nothing more than a 'cardboard shield.' Manchester Review of Law. Crime and Ethics, No. 1. Accessed October 1, 2018, from https:// 
www.humanities.manchester.ac.uk/medialibrary/law/main_site/ Research/Student_Law_Review1/MSLR_Vol1_1(Bouloy).pdf. Butler, J. (1990). Gender trouble. London: Routledge.

Butler, J. (1993). Bodies that matter. London: Routledge.

Butler, J. (2004a). Precarious life: The powers of mourning and violence. Verso.

Butler, J. (2004b). Undoing gender. Routledge.

Butler, J. (2005). Giving an account of oneself. Fordham University Press.

Butler, J. (2009). Frames of war. Verso.

Butler, J. (2015). Notes toward a performative theory of assembly. Harvard University Press.

Butler, J. (2016). Rethinking vulnerability and resistance. In J. Butler, Z. Gambetti, \& L. Sabsay (Eds.), Vulnerability in resistance (pp. 12-27). Duke University Press.

Butler, J., \& Athanasiou, A. (2013). Dispossession: The performative in the political. Wiley.

Butler, J. V., Serra, D., \& Spagnolo, G. (2020). Motivating whistleblowers. Management Science, 66(2), 605-621.

Cassematis, P. G., \& Wortley, R. (2013). Prediction of whistleblowing or non-reporting observation: The role of personal and situational factors. Journal of Business Ethics, 117(3), 615-634.

Cavarero, A. (2000). Relating narratives: Storytelling and selfhood. Routledge.

Cavarero, A. (2007). Horrorism: Naming contemporary violence. Columbia University Press.

Ceva, E., \& Bocchiola, M. (2019). Is whistleblowing a duty? Polity.

Cho, Y. J., \& Song, H. J. (2015). Determinants of whistleblowing within government agencies. Public Personnel Management, 44(4), 450-472.

Contu, A. (2014). Rationality and relationality in the process of whistleblowing: Recasting whistleblowing through readings of Antigone. Journal of Management Inquiry, 23, 393-406.

Cortina, L. M., \& Magley, V. J. (2003). Raising voice, risking retaliation: Events following interpersonal mistreatment in the workplace. Journal of Occupational Health Psychology, 8, 247-265.

Culiberg, B., \& Mihelič, K. K. (2016). The evolution of whistleblowing studies: A critical review and research agenda. Journal of Business Ethics, 146, 787-803.

Davern, M., Rodin, H., Beebe, T. J., \& Call, K. T. (2005). The effect of income question design in health surveys on family income, poverty and eligibility estimates. Health Services Research, 40, $1534-1552$.

De Graaf, G. (2010). A Report on reporting: Why peers report integrity and law violations in public organizations (pp. 767-779). Public Administration Review.

De Vaujany, F. X., Adrot, A., Boxenbaum, E., \& Leca, B. (Eds.). (2018). Materiality in institutions: Spaces, embodiment and technology in management and organization. Palgrave.

Devine, T. (2013). The whistleblower protection act burdens of proof: Ground rules for credible free speech rights. E-Journal of International and Comparative Labour Studies, 2(3), $137-152$.

Devine, T. (2015). International best practices for whistleblower statutes. In D. Lewis \& W. Vandekerckhove (Eds.), Developments in whistleblowing research (pp. 7-19). International Whistleblowing Research Network.

Devine, T., \& Maassarani, T. F. (2011). The corporate whistleblower's survival guide. Berrett-Koehler.

Dworkin, T. M., \& Baucus, M. S. (1998). Internal vs. external whistleblowers: A comparison of whistleblowing processes. Journal of Business Ethics, 17(12), 1281-1298.

Eisenstadt, L. F., \& Pacella, J. M. (2018). Whistleblowers need not apply. American Business Law Journal, 55(4), 665-719.
European Commission. (2017). Estimating the economic benefits of whistleblower protection in public procurement. Final report. European Commission.

European Commission. (2018). Whistleblower protection: Commission sets new, EU-wide rules. Press release in Brussels, 23 April. Accessed April 23, 2018, from http://europa.eu/rapid/press-relea se_IP-18-3441_en.htm

Feldman, Y., \& Lobel, O. (2010). The incentives matrix: The comparative effectiveness of rewards, liabilities, duties \& protections for reporting illegality. Texas Law Review, 87, 1151.

Ferguson, A., Hennessy, R., \& Nagel, M. (2018). Feminist perspectives on class and work. In N. Zalta (Ed.), The Stanford encyclopedia of philosophy. Springer.

Foster, K., \& Lound, C. (1993). A comparison of questions for classifying income. Survey Methodology of Bulletin, 32, 1-7.

Fotaki, M. (2006). Choice is yours: A psychodynamic exploration of health policy making and its consequences for the English National Health Service. Human Relations, 59(12), 1711-1744.

Fotaki, M. (2017). Relational ties of love - A psychosocial proposal for ethics of compassionate care in health and public services. Psychodynamic Practice, 23(3), 181-189.

Fotaki, M. (2019). Feminist ethics: Embodied relationality as a normative guide for management and organizations. In C. Neesham \& R. Macklin (Eds.), Handbook of philosophy of management. Springer. https://doi.org/10.1007/978-3-319-48352-8_15-1

Fotaki, M. (2021). Solidarity in crisis? Community responses to refugees and forced migrants in the Greek islands. Organization. https://doi.org/10.1177/13505084211051048.

Fotaki, M., Islam, G., \& Antoni, A. (Eds.). (2020). Business ethics and care in organizations. Routledge.

Fotaki, M., \& Kenny, K. (2019). Speaking out in contemporary organizations: What makes it possible? Report. University of Warwick.

Fotaki, M., Metcalfe, B., \& Harding, N. (2014). Writing materiality into organization theory. Human Relations, 67(10), 1239-1263.

Fotaki, M., Kenny, K., \& Scriver, S. (2015). Whistleblowing and mental health: A new weapon for retaliation? In D. Lewis \& W. Vandekerckhove (Eds.), Developments in whistleblowing research 2015 (pp. 106-121). International Whistleblowing Research Network.

Glazer, M. P., \& Glazer, P. M. (1989). The whistleblowers: Exposing corruption in government and industry. Basic.

Government Accountability Project. (2016). Why Whistleblowers Wait. Accessed November 5, 2020, from http://www.whistleblower. org/sites/default/files/whistleblowerguidejournalism.pdf; https:// whistleblower.org/resources/reports-and-publications/why-whist leblowers-wait-recommendations-to-improve-the-dodd-franklaws-sec-whistleblower-awards-program/

Government Accountability Project. (2017). Working with whistleblowers. A guide for journalists. Accessed November 5, 2018, from http://www.whistleblower.org/sites/default/files/whistleblowergu idejournalism.pdf

Government Accountability Project. (2018). Whistleblowing survival tips. Accessed November 5, 2018, from https://www.whistleblo wer.org/whistleblowing-survival-tips.

Grant, C. (2002). Whistleblowers: Saints of secular culture. Journal of Business Ethics, 39, 391-399.

Gunsalus, C. K. (1998). How to blow the whistle and still have a career afterwards. Science and Engineering Ethics, 4(1), 51-64.

Heimstädt, M., \& Dobusch, L. (2018). Politics of disclosure: Organizational transparency as multiactor negotiation. Public Administration Review, 78(5), 727-738.

Hersch, M. A. (2002). Whistleblowers-heroes or traitors? Individual and collective responsibility for ethical behaviour. Annual Reviews in Control, 26, 243-262.

IBA. (2021). Are whistleblowing laws working? A global study of whistleblower protection litigation. Accessed June 6, 2021, from 
https://www.ibanet.org/article/EE76121D-1282-4A2E-946CE2E059DD63DA

Jackson, D., Peters, K., Andrew, S., Edenborough, M., Halcomb, E., Luck, L., Salamonson, Y., Weaver, R., \& Wilkes, L. (2010). Trial and retribution: A qualitative study of whistleblowing and workplace relationships in nursing. Contemporary Nurse: A Journal for the Australian Nursing Profession, 36(1-2), 34-44.

Keenan, J. P. (2002). Comparing Indian and American managers on whistleblowing. Employee Responsibilities and Rights Journal, $14(2-3), 79-89$.

Kenny, K. (2018). Censored: Whistleblowers and impossible speech. Human Relations, 71(8), 1025-48.

Kenny, K. (2019). Whistleblowing: Toward a new theory. Harvard University Press.

Kenny, K., \& Fotaki, M. (2015). From gendered organizations to compassionate borderspaces: Reading corporeal ethics with Bracha Ettinger. Organization, 22(2), 183-199.

Kenny, K., \& Fotaki, M. (2019). Post-disclosure survival strategies: Transforming whistleblower experiences. NUI Galway: Galway, Ireland. Available from: https://www.whistleblowingimpact. org/wp-content/uploads/2019/06/19-Costs-of-Whistleblowing-ESRC-report.pdf. Accessed 28 Jan 2020.

Kenny, K., Fotaki, M., \& Scriver, S. (2019). Mental health as a weapon: Whistleblower retaliation and normative violence. Journal of Business Ethics, 160, 801-815.

Kenny, K., Fotaki, M., \& Vandekerckhove, W. (2020). Whistleblowing, organization and passionate attachment. Organization Studies, $41,323-343$.

Küpers, W. (2016). Embodied, relational practices of human and nonhuman in a material, social, and cultural nexus of organizations. On Culture: The Open Journal for the Study of Culture. http:// geb.uni-giessen.de/geb/volltexte/2016/12352/pdf/On_Culture_2_ Kuepers.pdf. Accessed 8 Aug 2021.

Lennane, J. (2012). What happens to whistleblowers, and why? Social Medicine, 6(4), 249-258.

Lewis, D. (2008). Ten years of public interest disclosure legislation in the UK: Are whistleblowers adequately protected? Journal of Business Ethics, 82(2), 497-507.

Lloyd, M. (2008). Towards a cultural politics of vulnerability. In T. Carver \& S. A. Chambers (Eds.), Judith Butler's precarious politics: Critical encounters (pp. 92-105). Routledge.

Mandalaki, E., \& Fotaki, M. (2020). The bodies of the commons: Towards a relational embodied ethics of the commons. Journal of Business Ethics. https://doi.org/10.1007/s10551-020-04581-7

Mansbach, A. (2009). Keeping democracy vibrant: whistleblowing as truth-telling in the workplace. Constellation: an International Journal of Critical and Democratic Theory, 16, 363-376.

Martin, B. (2013). Whistleblowing: A practical guide. Irene Publishing.

Martin, B. (2014). Research that whistleblowers want-and what they need.... In A. J. Brown, D. Lewis, R. Moberly, \& W. Vandekerckhove (Eds.), International handbook on whistleblowing research (pp. 497-521). Edward Elgar.

Martin, B., \& Rifkin, W. (2004). The dynamics of employee dissent: Whistleblower and organizational jiu-jitsu. Public Organization Review: A Global Journal, 4(3), 221-238.

Mesmer-Magnus, J. R., \& Viswesvaran, C. (2005). Whistleblowing in organizations: An examination of correlates of whistleblowing intentions, actions, and retaliation. Journal of Business Ethics, 62, 277-297.

Miceli, M. P., \& Near, J. P. (2013). An international comparison of the incidence of public sector whistle-blowing and the prediction of retaliation: Australia, Norway, and the US. Australian Journal of Public Administration, 72(4), 433-446.

Miceli, M. P., Near, J. P., \& Dworkin, T. M. (2009). A word to the wise: How managers and policy-makers can encourage employees to report wrongdoing. Journal of Business Ethics, 86(3), 379-396.

Miethe, D. (1999). Whistleblowing at work: Tough choices in exposing fraud, waste and abuse on the job. Westview Press.

Munro, I. (2017). Whistle-blowing and the politics of truth: Mobilizing 'truth grames' in the WikiLeaks case. Human Relations, 70(5), $519-543$

Murphy, A. V. (2011). Corporeal vulnerability and the new humanism. Hypatia, 26(3), 575-590.

Near, J. P., \& Miceli, M. P. (1985). Organizational dissidence: The case of whistleblowing. Journal of Business Ethics, 4(1), 1-16.

Near, J. P., Van Scotter, J. R., Rehg, M. T., \& Miceli, M. P. (2004). Does type of wrongdoing affect the whistle-blowing process? Business Ethics Quarterly, 14(2), 219-242.

Nyreröd, T., \& Spagnolo, G. (2019). Myths and numbers on whistleblower rewards. Regulation \& Governance, 15, 82-97.

Olesen, T. (2018). The democratic drama of whistleblowing. European Journal of Social Theory, 21(4), 508-525.

Oliver, D. (2003). Whistle-blowing engineer. Journal of Professional Issues in Engineering Education and Practice, 129(4), 246-256.

Park, H., Bjørkelo, B., \& Blenkinsopp, J. (2020). External whistleblowers' experiences of workplace bullying by superiors and colleagues. Journal of Business Ethics, 161, 591-601.

Park, H., Blenkinsopp, J., Oktem, M. K., \& Omurgonulsen, U. (2008). Cultural orientation and attitudes toward different forms of whistleblowing: A comparison of South Korea, Turkey, and the UK. Journal of Business Ethics, 82(4), 929-939.

Parmerlee, M. A., Near, J. P., \& Jensen, T. C. (1982). Correlates of whistleblowers' perceptions of organizational reprisals. Administrative Science Quarterly, 27, 17-34.

Peters, K., Luck, L., Hutchinson, M., Wilkes, L., Andrews, S., \& Jackson, D. (2011). The emotional sequelae of whistleblowing: Findings from a qualitative study. Journal of Clinical Nursing, 20, 2907-2914.

Pullen, A., \& Rhodes, C. (2014). Corporeal ethics and the politics of resistance in organizations. Organization, 21(6), 782-796.

Pullen, A., \& Rhodes, C. (2015). Ethics, embodiment and organizations. Organization, 22(2), 159-175.

Qusqas, F., \& Kleiner, B. H. (2001). The difficulties of whistleblowers finding employment. Management Research News, 24, 97-100.

Rehg, M. T., Miceli, M. P., Near, J. P., \& Van Scotter, J. R. (2008). Antecedents and outcomes of retaliation against whistleblowers: Gender differences and power relationships. Organization Science, 19(2), 221-240.

Rothschild, J. (2013). The fate of whistleblowers in nonprofit organizations. Nonprofit and Voluntary Sector Quarterly, 42, 886-901.

Rothschild, J., \& Miethe, T. D. (1999). Whistle-blower disclosures and management retaliation: The battle to control information about organization corruption. Work and Occupations, 26, 107-128.

Roulet, T. J., \& Pichler, R. (2020). Blame game theory: Scapegoating, whistleblowing and discursive struggles following accusations of organizational misconduct. Organization Theory, 1(4), 2631787720975192.

Sims, R. L., \& Keenan, J. P. (1999). A cross-cultural comparison of managers' whistleblowing tendencies. International Journal of Value-Based Management, 12(2), 137-151.

Smith, A. (2014). 'There were hundreds of us crying out for help': The afterlife of the whistleblower. The Guardian, 22 November. Accessed March 19, 2020, from https://www.theguardian. com/society/2014/nov/22/there-were-hundreds-of-us-cryingout-for-help-afterlife-of-whistleblower

Smith, R., \& Brown, A. J. (2008). The good, the bad and the ugly: Whistleblowing outcomes. In A. J. Brown (Ed.), Whistleblowing in the Australian public sector: Enhancing the theory and practice of internal witness management in public sector 
organizations (pp. 129-134). The Australian National University Press.

Stubben, S., \& Welch, K. (2020). Evidence on the use and efficacy of internal whistleblowing systems. Journal of Accounting Research, 58(2), 473-518.

Su, X., \& Xing, N. (2018). Institutional anticorruption in China: Effectiveness on bribery incidence. Public Administration Review, 79(4), 538-551.

Tavakoli, A. A., Keenan, J. P., \& Cranjak-Karanovic, B. (2003). Culture and whistleblowing an empirical study of Croatian and United States managers utilizing Hofstede's cultural dimensions. Journal of Business Ethics, 43(1-2), 49-64.

Taylor, E. Z., \& Curtis, M. B. (2010). An examination of the layers of workplace influences in ethical judgments: Whistleblowing likelihood and perseverance in public accounting. Journal of Business Ethics, 93(1), 21-37.

Transparency International Ireland. (2017). Speak up report. https:// www.transparency.ie/sites/default/files/17.12.13_speak_up_ report_ie_final.pdf. Accessed 8 Aug 2021.

Tsahuridu, E. E., \& Vandekerckhove, W. (2008). Organisational whistleblowing policies: Making employees responsible or liable? Journal of Business Ethics, 82, 107-118.

Tyler, M. (2019). Judith Butler and organization theory. Routledge.

Vachhani, S. (2012). The subordination of the feminine? Developing a critical feminist approach to the psychoanalysis of organizations. Organization Studies, 33, 1237-1255.

Vachhani, S. J., \& Pullen, A. (2019). Ethics, politics and feminist organizing: Writing feminist infrapolitics and affective solidarity into everyday sexism. Human Relations, 72, 23-47.

Vadera, A. K., Aguilera, R. V., \& Caza, B. B. (2009). Making sense of whistle-blowing's antecedents: Learning from research on identity and ethics programs. Business Ethics Quarterly, 19(4), 553-586.

Van Portfliet, M. (2020). Resistance will be futile? The stigmatization (or not) of whistleblowers. Journal of Business Ethics. https://doi.org/10.1007/s10551-020-04673-4
Vandekerckhove, W. (2006). Whistleblowing and organizational social responsibility: A global assessment. Routledge.

Vandekerckhove, W., James, C., \& West, F. (2013). Whistleblowing - the inside story. University of Greenwich.

Vandekerckhove, W., \& Langenberg, S. (2012). Can we organize courage? Implications of Foucault's parrhesia. Electronic Journal of Business Ethics and Organisation Studies, 17(2), 35-44.

Vandekerckhove, W., \& Phillips, A. (2019). Whistleblowing as a protracted process: A study of UK whistleblower journeys. Journal of Business Ethics, 159(1), 201-219.

Vandekerckhove, W., \& Tsahuridu, E. (2010). Risky rescues and the duty to blow the whistle. Journal of Business Ethics, 97(3), 365-380.

Verschoor, C. C. (2012). Retaliation for whistleblowing is on the rise. Strategic Finance, 95(5), 13-15.

Weiskopf, R., \& Tobias-Miersch, Y. (2016). Whistleblowing, parrhesia and the contestation of truth in the workplace. Organization Studies, 37(11), 1621-1640.

Weiskopf, R., \& Willmott, H. (2013). Ethics as critical practice: The "pentagon papers", deciding responsibly, truth-telling, and the unsettling of organizational morality. Organization Studies, 34, 469-493.

Wilkies, L. M., Peters, K., Weaver, R., \& Jackson, D. (2011). Nurses involved in whistleblowing incidents: Sequelae for their families. Collegian, 18(3), 101-106.

Publisher's Note Springer Nature remains neutral with regard to jurisdictional claims in published maps and institutional affiliations. 